\section{Commentary: Cardioplegia for immature hearts utilized in adult hearts: What is at stake?}

\author{
Daniel H. Buitrago, MD, PhD, and \\ Tomas A. Salerno, MD
}

Heart surgery is myocardial protection. Inadequate protection leads to poor short- and long-term outcomes. Myocardial protection during minimally invasive cardiac surgery (MICS) is challenging because a surgeon operates in a confined space requiring a bloodless field. This has led surgeons to utilize cardioplegia solutions that allow for safe myocardial protection with a single infusion. This facilitates the flow of the procedure, decreasing the morbidity and mortality associated with long cardiopulmonary bypass and crossclamp times. Custodiol histidine-tryptophan-ketoglutarate (HTK) solution has been used in adult heart surgery for a long time. This is in contrast to del Nido (DN) cardioplegia, designed for immature hearts, which is now being employed in conventional surgery and MICS in adults.

HTK is an intracellular crystalloid solution, known to provide up to 3 hours of protection with single infusion. ${ }^{1,2}$ On the other hand, DN cardioplegia is an extracellular crystalloid solution and, as mentioned, was designed for protection of immature hearts. ${ }^{3}$ It allows preservation of intracellular phosphate concentration, maintains intracellular $\mathrm{pH}$, and reduces intracellular damage by calcium ion influx during ischemic arrest. The safety and efficacy of HTK cardioplegia in adult and pediatric patients have been well established. ${ }^{4-6}$ Extrapolation of DN cardioplegia to adult hearts remains unclear, lacking basic science investigation.

\footnotetext{
From the Division of Cardiothoracic Surgery, University of Miami Miller School of Medicine and Jackson Memorial Hospital, Miami, Fla.

Disclosures: The authors reported no conflicts of interest.

The Journal policy requires editors and reviewers to disclose conflicts of interest and to decline handling or reviewing manuscripts for which they may have a conflict of interest. The editors and reviewers of this article have no conflicts of interest.

Received for publication Dec 18, 2020; revisions received Dec 18, 2020; accepted for publication Dec 18, 2020; available ahead of print Dec 29, 2020.

Address for reprints: Tomas A. Salerno, MD, Division of Cardiothoracic Surgery, University of Miami Miller School of Medicine, Jackson Memorial Hospital, 1611 NW 12th Ave, R-114, Miami, FL 33136 (E-mail: tsalerno@med.miami.edu). J Thorac Cardiovasc Surg 2022;164:e175-6 $0022-5223 / \$ 36.00$

Copyright (c) 2020 by The American Association for Thoracic Surgery https://doi.org/10.1016/j.jtcvs.2020.12.080
}

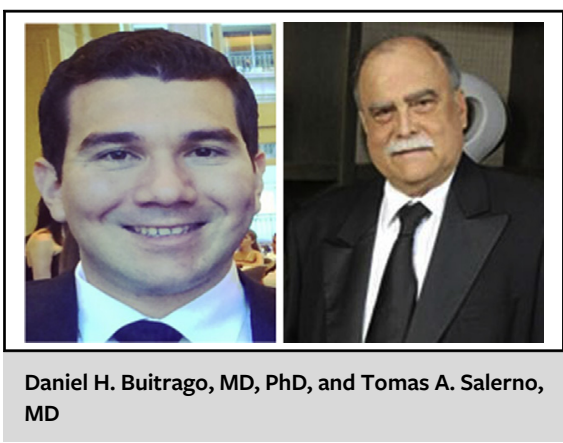

CENTRAL MESSAGE

Minimally invasive cardiac surgery requires distinctive surgical skills, and del Nido cardioplegia facilitates the procedure with single infusion.

Lee and colleagues ${ }^{7}$ examine the efficacy and safety of DN compared with HTK in a propensity-matched cohort of 228 patients undergoing MICS. The authors demonstrate similar clinical outcomes. However, peak levels of cardiac isoenzyme were significantly lower in patients receiving DN cardioplegia when ischemic times did not exceed 100 minutes. The enzyme levels were higher when ischemic times exceeded 100 minutes compared with HTK.

We congratulate the authors for their efforts and elegant study design. Nevertheless, definitive conclusions cannot be made as to the best method of myocardial protection for MICS because the study evaluated 2 cardioplegia solutions with limited sample size. Additionally, to further determine DN cardioplegia's effectiveness and safety in MICS, larger prospective clinical trials (with interventions using long aortic clamping periods) and basic science research in adult hearts will be required. Until then, we will have to rely on clinical reports to justify its continued use.

\section{References}

1. Bretschneider HJ. Myocardial protection. Thorac Cardiovasc Surg. 1980;28: 295-302.

2. Gebhard MM, Preusse CJ, Schnabel PA, Bretschneider HJ. Different effects of cardioplegic solution HTK during single or intermittent administration. Thorac Cardiovasc Surg. 1984;32:271-6.

3. del Nido PJ, Wilson GJ, Mickle DA, Bush BG, Rebeyka IM, Klement P, et al. The role of cardioplegic solution buffering in myocardial protection. A biochemica and histopathological assessment. J Thorac Cardiovasc Surg. 1985;89:689-99.

4. Takeuchi K, Cao-Danh H, Kawai A, Ohkado A, Konishi H, McGowan FX, et al. Prolonged preservation of the blood-perfused canine heart with glycolysispromoting solution. Ann Thorac Surg. 1999;68:903-7. 
5. Talwar S, Bhoje A, Sreenivas V, Makhija N, Aarav S, Choudhary SK, et al. Comparison of del Nido and St Thomas cardioplegia solutions in pediatric patients: a prospective randomized clinical trial. Semin Thorac Cardiovasc Surg. 2017;29: 366-74.

6. Talwar S, Chatterjee S, Sreenivas V, Makhija N, Kapoor PM, Choudhary SK, et al. Comparison of del Nido and histidine-tryptophan-ketoglutarate cardioplegia solutions in pediatric patients undergoing open heart surgery: a prospective randomized clinical trial. J Thorac Cardiovasc Surg. 2019;157: 1182-92.e1181.

7. Lee C-H, Kwon Y, Park SJ, Lee JW, Kim JB. Comparison of del Nido and histidine-tryptophan-ketoglutarate cardioplegic solutions in minimally invasive cardiac surgery. J Thorac Cardiovasc Surg. 2022;164:e161-71. 